Talía. Revista de estudios teatrales

ISSN-e: 2659-806X

http://dx.doi.org/10.5209/TRET.63220

\title{
Entre ética y estética: la censura del teatro de Agustín Moreto ${ }^{1}$
}

\author{
María Luisa Lobato*
}

Recibido: 16 de octubre de 2018 / Aceptado: 19 de noviembre de 2018

Resumen. Las comedias de Agustín Moreto tuvieron una gran fortuna editorial en especial en el siglo XVIII, en que fueron -junto a las de Calderón- las más editadas. Resultado de ello es que se conservan numerosos ejemplares impresos y algunos manuscritos de ese periodo, varios con marcas y notas de censura. Nos centramos aquí en ejemplares conservados en la Biblioteca Nacional de España y en la Biblioteca Histórica Municipal de Madrid, donde se guarda una importante colección de comedias sueltas impresas en el siglo XVIII. También se observan ejemplares de los siglos XVII y XIX. Dilucidar si estas notas manuscritas sobre las comedias de Moreto fueron realizadas por calificadores del Santo Oficio, por autores de comedias o miembros de las compañías, incluso por impresores, no es tarea fácil. Se hace aquí una incursión en ejemplares conservados y hasta ahora no analizados desde ese punto de vista.

Palabras clave: Moreto, Censura, Teatro, Comedia, Siglo de Oro, Santo Oficio, Compañías teatrales, Impresos, Manuscritos

\section{Ethics and Esthetics: Censorship in Agustin Moreto's Theater}

\begin{abstract}
The plays of Agustín Moreto enjoyed great publishing success especially in the 18th century, in that they were the most edited, together with those of Calderón. The numerous printed copies and some manuscripts that are dated from that period, some of which have censorship markings and notes, evidence this result. We limit our scope to those copies that are stored in the Biblioteca Nacional of Spain and in the Biblioteca Histórica Municipal of Madrid, where an important collection of printed sueltas of the plays from the 18th century are housed. In addition, there are other copies dating from the 17th and 19th centuries. It is not an easy task in trying to explain if these written notes present in Moreto's plays were made by officers of the Holy Office, by autores of plays or by members of the theatre companies, or even by the printers. The aim here is to carry out a study of these preserved copies that have not been analysed from this perspective until now.
\end{abstract}

Key words: Moreto, Censorship, Play (Comedia), Theatre companies, Printed texts, Manuscripts

Cómo citar: Lobato, M. L. (2019). Entre ética y estética: la censura del teatro de Agustín Moreto, en Talía. Revista de estudios teatrales, 1, 135-161.

\footnotetext{
1 Este trabajo se enmarca en el proyecto de investigación Escritura teatral colaborativa en el Siglo de Oro: análisis, interpretación y nuevos instrumentos de investigación (Centenario de Agustín Moreto, 1618-2018), con sede en la Universidad de Burgos, financiado por el Ministerio de Ciencia, Innovación y Universidades-Fondos FEDER (Proyecto I+D Excelencia FFI2017-83693-P).

* Universidad de Burgos.
} 


\section{Introducción}

Escribía Lorenzo [Cano] en Madrid a propósito de El lindo don Diego un 16 de julio de 1816: "No hallo reparo en que se permita su representación, con tal que se ejecute según está corregida". He aquí una frase estereotipo de censor, que puede encontrarse manuscrita en varias comedias que se han transmitido impresas sueltas. El mismo ejemplar lo revisaba dos días más tarde el doctor don Francisco Ramiro y Arcayos, Arcipreste de la Iglesia Magistral de Alcalá de Henares y Vicario de la villa de Madrid y su partido, miembro de la Inquisición, el cual firmaba también en Madrid la aprobación sin poner reparos, con la consabida frase: "que la comedia antecedente titulada El lindo don Diego se pueda representar en los teatros públicos de esta corte, mediante a que habiendo sido reconocida, no contiene al parecer [...] cosa que se oponga a nuestra santa fe y buenas costumbres". Otras aprobaciones de la misma se leen a continuación variando las fechas: el 25 de julio del Conde de Casillas de Velasco; otra mano el 8 de agosto dice: "Represéntese. León [de la Cámara Cano]". La obra tenía aprobaciones manuscritas de dos años antes, en concreto, del 14 de noviembre de 1814. El colofón de esta edición de El lindo don Diego indica que se vendía en la Librería de Quiroga, calle de la Concepción Jerónima, junto a Barrio Nuevo [entre 1785 y 1800]. La sucesión de aprobaciones deja constancia de que este ejemplar circuló en manos de la censura durante varios años, recibiendo aprobaciones para puestas en escena separadas en el tiempo. Se encuentra en $\mathrm{BHM}^{2}$ Tea 1-122-10, c 2.

Lo indicado en el párrafo anterior deja constancia de cómo un ejemplar de una de las comedias señeras de Agustín Moreto circuló en manos de la censura durante varios años y recibió aprobaciones para puestas en escena distantes en el tiempo. Es una muestra de un modo de actuación de los censores del que no siempre hay pruebas, por lo que el testimonio anterior tiene especial interés.

Nos proponemos en este artículo, en primer lugar, puntualizar la atribución de algunas obras que han sido adjudicadas a Moreto hasta el momento. Pero, sobre todo, observar el trabajo de la censura en los siglos XVII, XVIII y XIX en obras manuscritas e impresas que este dramaturgo escribió solo o en colaboración con otros autores.

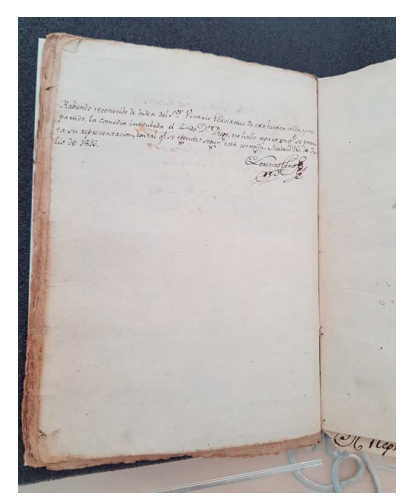

Ilustración 1.

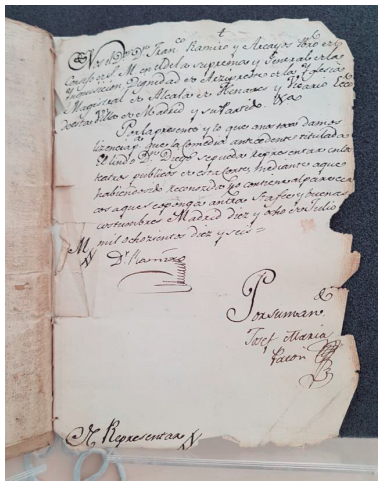

Ilustración 2.

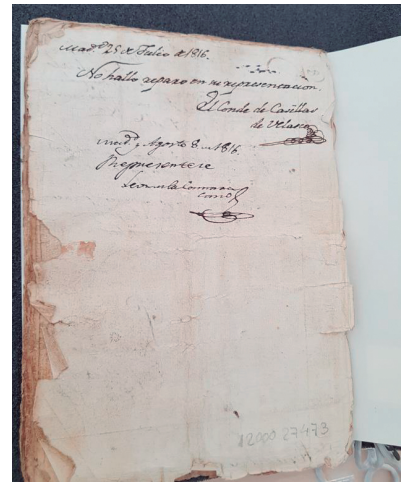

Ilustración 3.

$2 \mathrm{BHM}=$ Biblioteca Histórica Municipal de Madrid. BNE= Biblioteca Nacional de España. 
Se sumará a ello el intento de interpretación de las razones que pudieron llevar a sus autores a realizar las marcas manuscritas en los textos que se han conservado, tras la observación de un centenar de ellos. Por último, se establecerán algunas conclusiones que se derivan del análisis anterior.

\section{Estado de la cuestión, puntualizaciones y objetivo de este estudio}

No voy a detenerme aquí en la censura de la mayoría de obras de Moreto que se conservan manuscritas durante el siglo XVII, tanto autógrafas como no, ya bien tratadas hace pocos años por Héctor Urzáiz y Gema Cienfuegos [2013], como no sea para sintetizar en unos párrafos lo tratado en aquella aportación.

De ese artículo, que contiene noticias muy interesantes de la censura moretiana en el siglo XVII, hay que descartar dos obras que no son de este dramaturgo, según hemos podido comprobar en la investigación que llevamos a cabo en PROTEO sobre la producción de Moreto: Travesuras son valor o Sancho el Bueno y Sancho el Malo y El rosario perseguido. Las obras que se tratan en el artículo son tres escritas en solitario: El poder de la amistad, San Franco de Sena o el lego del Carmen y El parecido, y seis en las que Moreto colaboró con otros autores: La adúltera penitente, El príncipe perseguido, El rey Enrique el Enfermo, El bruto de Babilonia, La mejor luna africana y Vida y muerte de san Cayetano.

Los censores que dejaron su dictamen manuscrito en más ocasiones fueron Juan Navarro de Espinosa (en vida de Moreto) y Francisco de Avellaneda (en el año de la muerte del dramaturgo, 1669, y años después). La firma del fiscal Fermín de Sarasa aparece bajo el lugar y la fecha de 1669 en varias obras y también se lee con otras más tardías en algunas de las obras mencionadas. Otros nombres de censores, fiscales, protectores de comedias y calificadores del Santo Oficio se repitieron menos en este conjunto de obras, pero dejan constancia de haberlas revisado. Es el caso de Lanini, Cañizares, Rueda y Cuevas, Vera y Tassis, Boyl y Bueno.

Faltaría en el estudio anterior únicamente ocuparse de los manuscritos de Lo que puede la aprehensión (BNE, ms. 14916), escrita por Moreto, con censuras de Francisco de Avellaneda y Fermín de Sarasa, y de Los mártires de Madrid (BNE, ms. 16797 y ms. 17100), obra de varios autores, con censura de Francisco Bueno. Sin datos de quién pudo ser el censor, pero con anotaciones de "No", está también el ejemplar manuscrito de Trampa adelante (BNE, ms. 14921).

Las dos primeras comedias están incluidas en la base de datos sobre Censuras $y$ licencias en manuscritos impresos teatrales (http://www.clemit.es/), que dirige el propio Urzáiz. Una vez examinadas, podemos indicar que las censuras de Lo que puede la aprehensión en el ms. 14916 BNE están firmadas al final de la $1^{\text {a jornada }}$ por los ya citados Francisco de Avellaneda y Fermín de Sarasa el 3 de octubre de 1669 , como "vista y aprobada", cuando faltaba menos de un mes para la muerte de Moreto, ocurrida el 28 de octubre de 1669. No es posible saber si es de alguno de ellos la palabra "No" y la marca a la izquierda de los vv. 281-304, que forman parte del largo parlamento de Fenisa, dama, con el que casi se inicia la comedia. Los versos, en concreto, se refieren a la fama y al honor femeninos, y dicen así:

No ha de examinarse un riesgo por tan costoso camino 


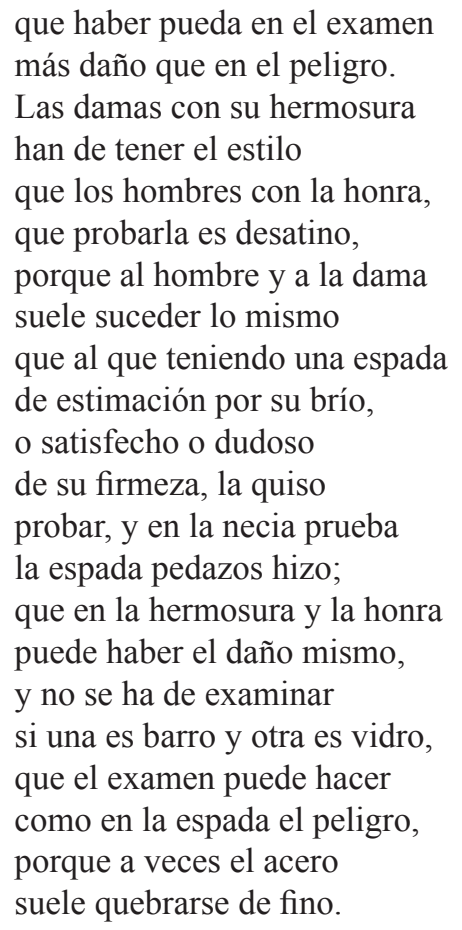

Lo cierto es que pasajes de este tenor abundan en la obra de Moreto y, en general, en todo el Siglo de Oro, desde luego muchos de ellos sin marca alguna. No hay más indicaciones manuscritas en la obra hasta casi al final en que una cruz podría ser otra marca de la censura al mismo tema, esta vez en boca del gracioso y en menos versos [vv. 2991-2993]:

Colmillo ¿Yo? Pues si tú en eso dabas, ¿le he de quitar yo a tu prima la buena voz, que es su fama?

No deja de sorprender que la censura firme y rubrique al final de la $1^{\mathrm{a}}$ jornada de esta comedia, como si alguien hubiera tenido prisa en revisarla para darla por buena, cuando Moreto aún estaba vivo, pero ya muy enfermo.

En cuanto a Los mártires de Madrid, el ms. 17100 de la BNE termina con la aprobación de Francisco Bueno para una representación de esta comedia de Cáncer, Moreto y Matos en Huesca el 2 de enero de 1698. El texto tiene ampliaciones en versos de arte mayor que no están, por ejemplo, en el que sirvió de base a la editora crítica del mismo, Roberta Alviti. Se deja aquí ilustración de seis páginas completas del manuscrito de 1698 en las que se leen varios fragmentos que no estaban en la princeps y que más parecen un añadido útil para la compañía en una representación finisecular. En concreto, en el texto base no aparecen los versos que aquí se leen al final de la p. 24, desde el siguiente a "la santa naturaleza", todos los de las pp. 25 y 26, y se retoma el texto en el sexto verso del parlamento de Celín en la p. 27, donde dice "Puesto que bien no la vieses". El estudio crítico de esta obra, que se lleva a cabo en la actualidad, nos dará luces seguro sobre el sentido de estas marcas y su 
vinculación a una mano que atendía a la ética de la obra o a la estética, que vio en el manuscrito añadidos posteriores a lo impreso en el texto base y quiso eliminarlos para la representación y, quizá, para ediciones posteriores. Solo la tradición crítica de esta comedia podrá aclarárnoslo.

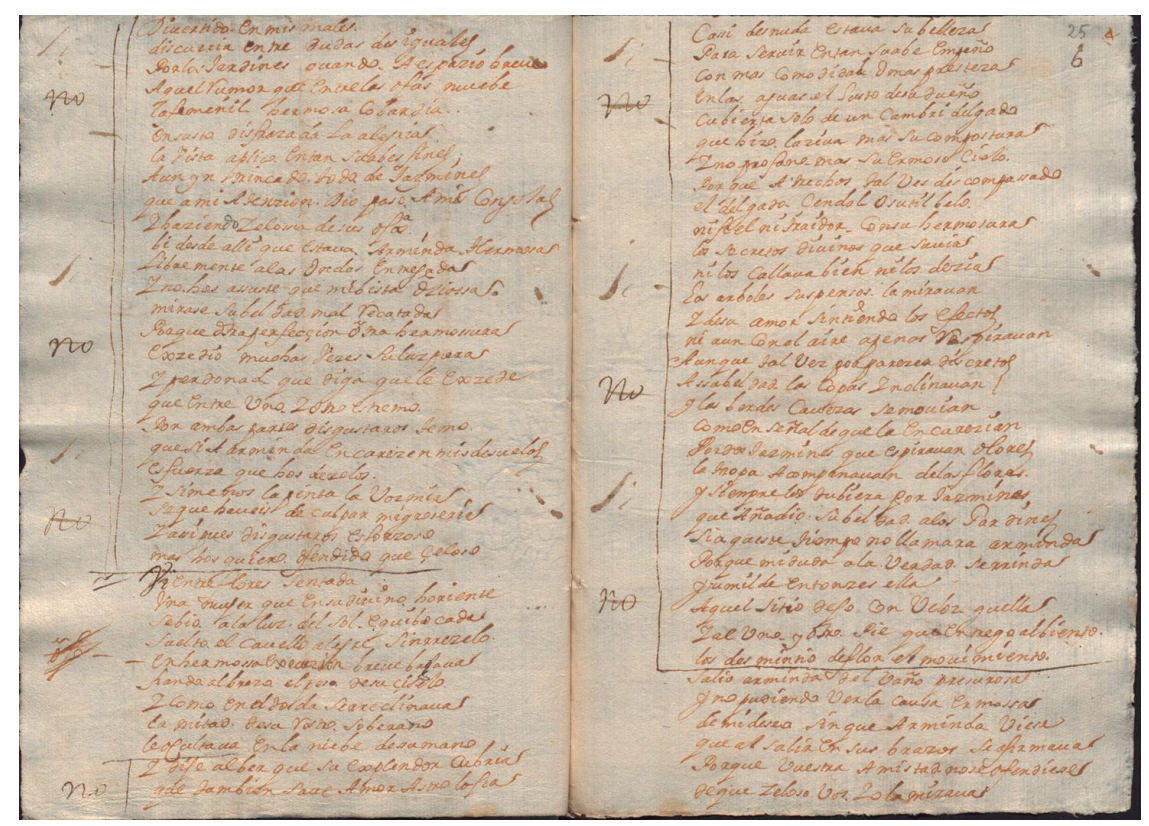

Ilustración 4.

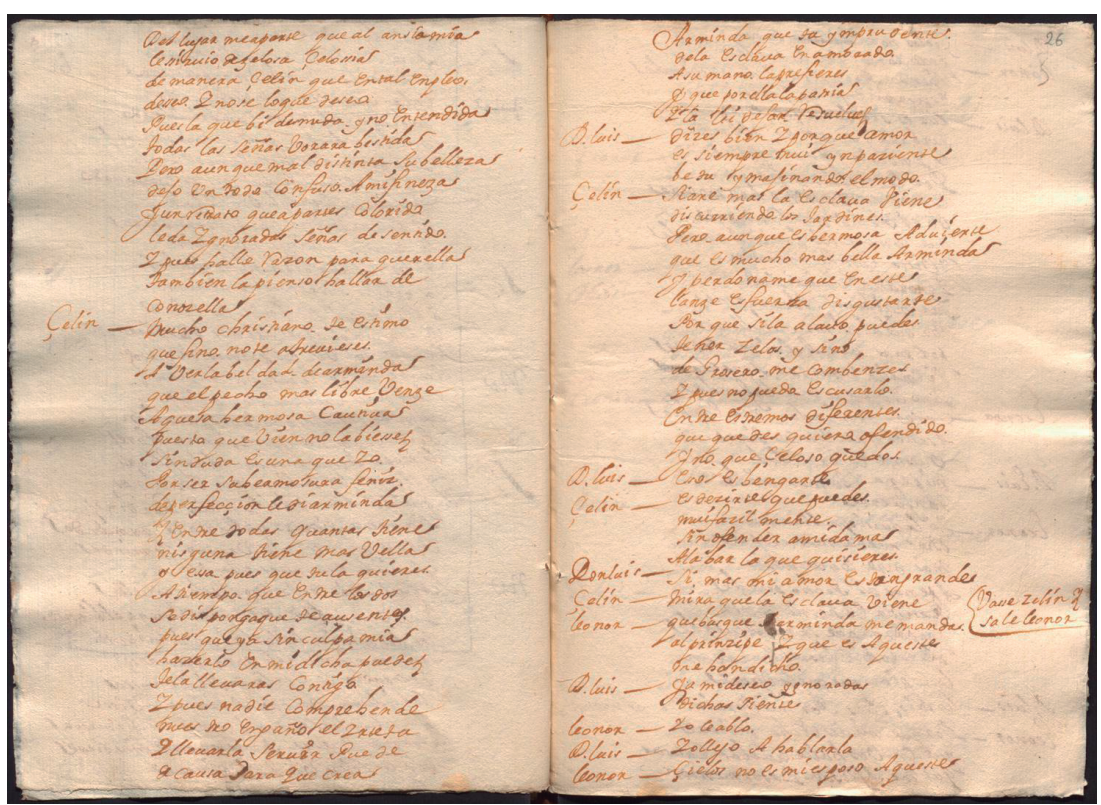

Ilustración 5. 


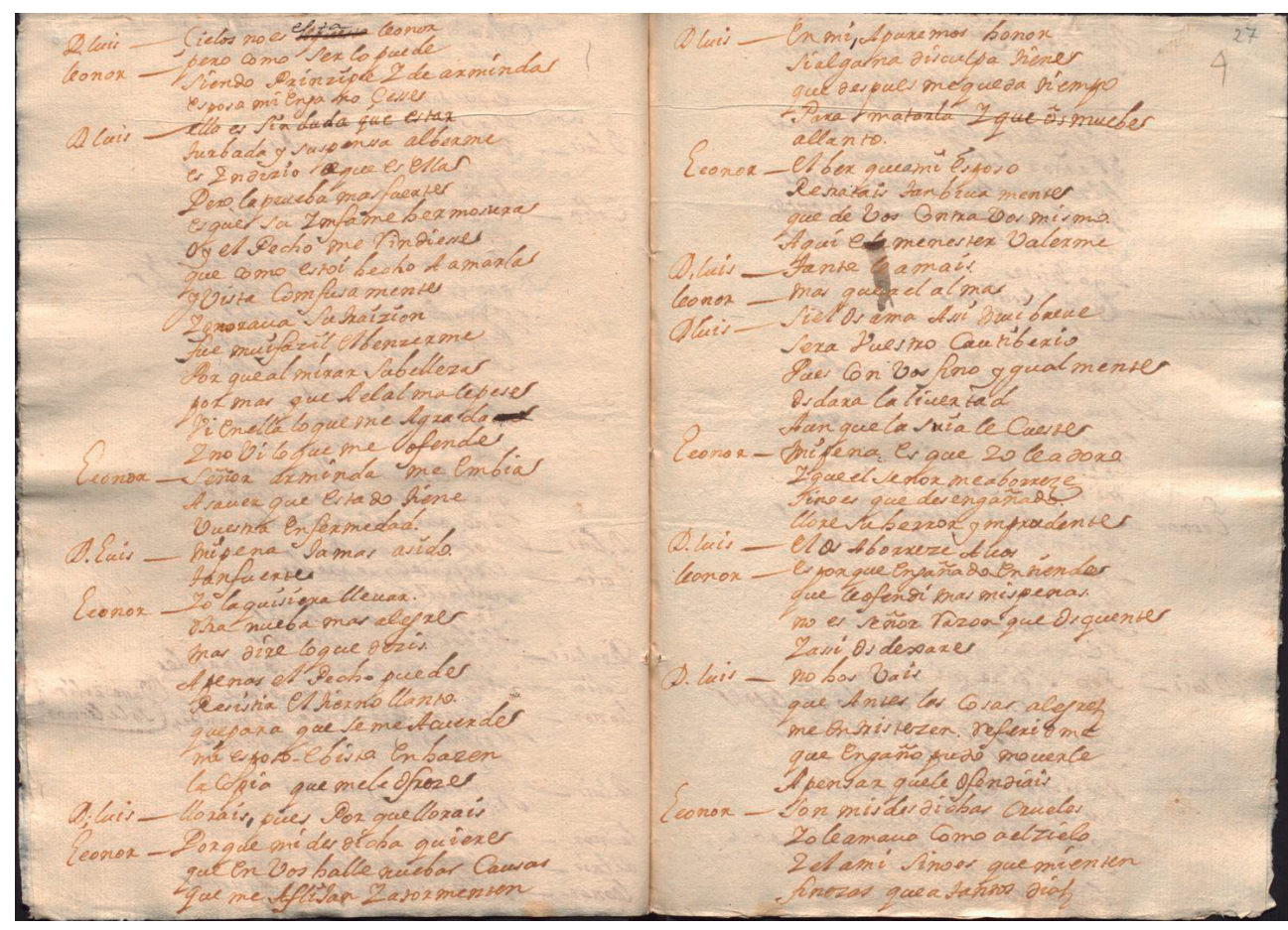

Ilustración 6.

La tercera comedia, la divertida Trampa adelante, contiene en el manuscrito mencionado, BNE ms.14921, diversas marcas que parecen ser de la censura en fols. $24 \mathrm{v}, 33 \mathrm{v}$ y 49 . En este último folio, los versos afectados se relacionan con una de las imágenes más utilizadas por Moreto en diversas comedias, la del enfermo que toma lo que no le conviene. El motivo llega desde Petrarca, a través de Ausías March y Garcilaso a la literatura española y el mismo Moreto lo emplea en El desdén, con el desdén, con la peculiaridad de que en el ejemplar R 35352 de la BNE también aparece el pasaje recuadrado [vv. 1315-1344]. Antíoco y Seleuco [vv. 2389-2392] repite dos versos de forma idéntica a los que aquí son vv. 2668-2669. En Trampa adelante el conjunto de los versos enmarcados por un "No" corresponden a un parlamento único de don Juan, mientras en Antíoco y Seleuco iniciaban una tirada de versos en boca del príncipe Antíoco. Si el "No" fuese de mano del censor, parecería que el motivo del desagrado era el amor enardecido en extremo de un galán por su dama:

Don JuAn Suspende, Leonor, el llanto, que no podrá, aunque me agravias, resistir mi ardiente fuego el dulce riesgo del agua. El enfermo, a quien la sed de la calentura abrasa, se arroja a perder la vida por vencer bebiendo el ansia. 
Mi amor, enfermo de agravios, arde en la violencia falsa de la sed de tus cariños; pues no le muestres el agua, que si en tus ojos, Leonor, mira el cristal que derramas, por no sufrir lo que aflige, ha de beber lo que mata. [vv. 2664-2679]

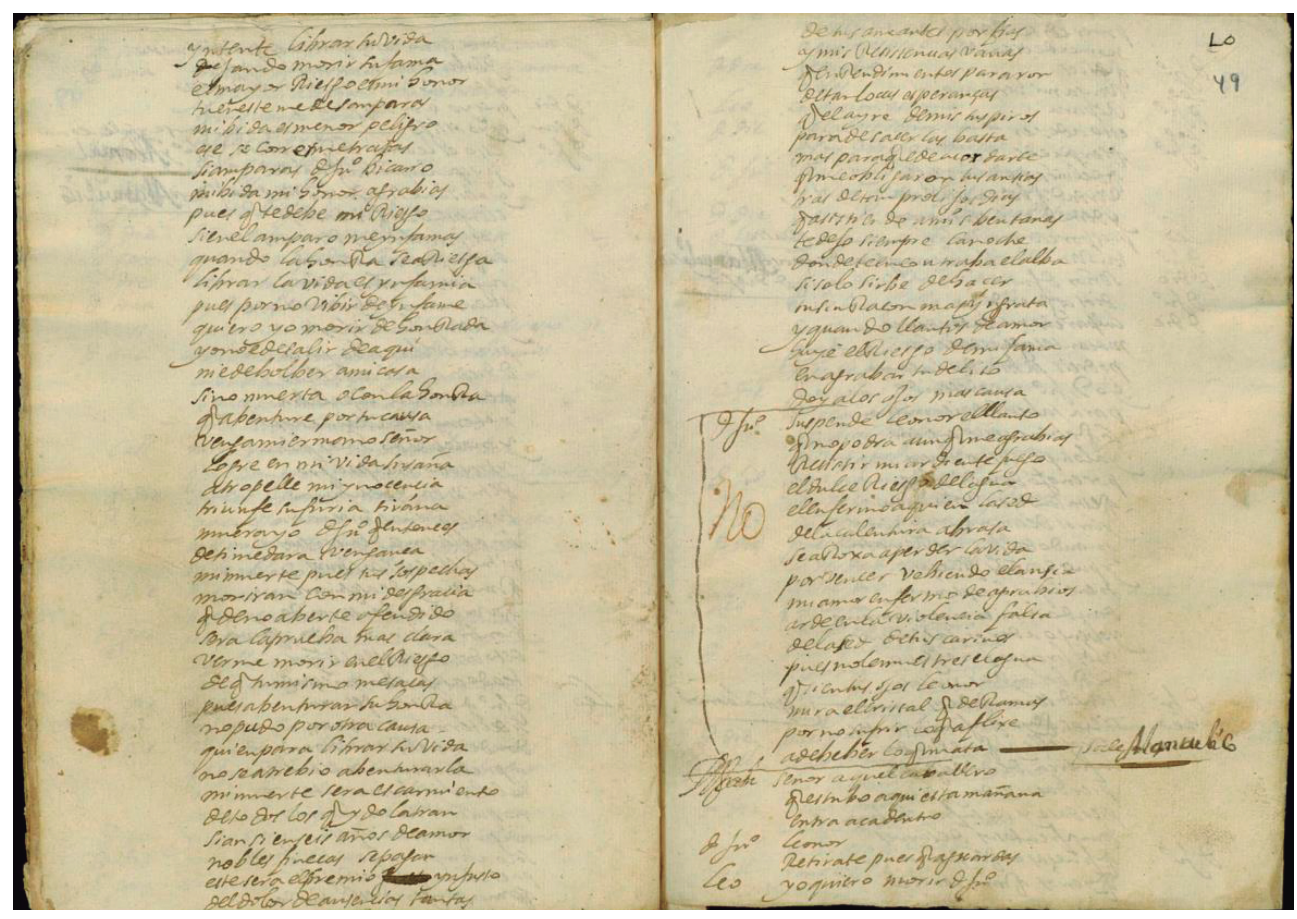

Ilustración 7.

Podría ser interesante ver qué otros pasajes aparecen recuadrados y con un "No" escrito por la misma mano. Uno de ellos es, por ejemplo, el que ocupa los vv. 13841398, en el que existe una disputa a tres voces entre don Juan, el gracioso Millán y un esportillero que reclama su paga. Acaba con una invocación al diablo: "Llévense os diabros la casa / e a min porque vine acá" [vv. 1397-1398].

Por tanto, una vez recordado el artículo de Urzáiz y Cienfuegos [2013] se ha puntualizado la atribución de dos obras allí tratadas, que ya podemos decir que no son de Moreto. He añadido aquí noticia de tres manuscritos con notas de censura que faltaban. Es momento de centrarnos en la actuación de la censura en obras manuscritas e impresas escritas por Moreto solo o en colaboración con otros dramaturgos, de las que hemos examinado un centenar para elaborar esta aportación ${ }^{3}$.

3 Mi agradecimiento especial a Pilar Egoscozábal, Jefa del Servicio de Reserva Impresa de la BNE, que colaboró de manera muy eficaz en la localización y consulta de textos provenientes de la BNE. También a la 
En algunos casos la censura tiene fecha del siglo XVII, pero en muchos otros los censores son ya del siglo XVIII y del XIX, lo que nos da la oportunidad de observar, en primer lugar, las notas de la censura de ese período relativas a Moreto - de las que no existe estudio, hasta donde sabemos- y, una vez realizado ese análisis, podría calibrarse si existió cambio en la valoración de pasajes comprometidos entre esos tres siglos cuando, sin duda, los gustos estéticos y quizá también las consideraciones morales sobre el teatro habían cambiado. Ese periodo, en especial el siglo XVIII, fue especialmente fructífero para las representaciones del teatro moretiano, que se situó junto al de Calderón en el más transmitido por la imprenta y más representado en los escenarios.

\section{Moreto y la censura de sus obras escritas en solitario}

Sería interesante, pensamos, saber qué criterios sigue la censura al leer textos impresos en el siglo XVIII, pues es posible esperar un cierto cambio en el modo de afrontarlos. Tomemos, por ejemplo, el texto impreso de la comedia La misma conciencia acusa, BHM Tea 1-125-14, c. Las censuras, en que se pide al censor y fiscal de comedias que "reconozcan" la comedia "y hecho, informen", se solicitan el 10 de diciembre de 1753 y están fechadas el 13 de diciembre en Madrid por Nicolás González Mar[tíne]z, censor de comedias, el cual escribe y firma: "He visto esta comedia de La misma conciencia acusa y no tiene reparo que embarace su representación, si fuese us[ted] servido de permitir la licencia. Así lo siento". A continuación, con términos similares, firma Francisco de Cuadros, fiscal de comedias que moriría algunos años más tarde, en 1757. Solo una semana después, el 20 de diciembre, se recogen las opiniones de censor y fiscal y se concede: "ejecútese". Ese ejemplar contiene solo unas enmiendas manuscritas sobre el texto, que corresponden a los vv. 27 y 28, en los que Tirso, villano, recrimina a la también villana Laureta: "que a más de ser alcahueta, / os retoza el alcacer", que se sobreescribe de la siguiente manera: "que huyendo de la alcahueta / sois lo que no queréis ser", con lo que se da un tono de mayor moralidad a la actividad de Laureta.

Como si la censura no evolucionara entre siglos, en el XIX se pueden leer las líneas manuscritas en el ejemplar impreso suelto de la comedia De fuera vendrá, que lleva fecha de 1796 en la Librería Quiroga, uno de cuyos ejemplares se custodia en BHM Tea 1-103-11, b3. No hay en él ningún tipo de marcas. Tras el colofón se indica: "No hallo inconveniente en que se permita representar la anterior comedia titulada De fuera vendrá quien de casa nos echará, la tía y la sobrina, cuyas foj[as] he rubricado. Madrid, 18 de abril de 1826"; firma y rúbrica de Arellano. Muchas señales hay, sin embargo, en el ejemplar BNE T 14796_23 de la misma

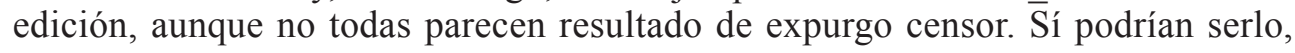

\footnotetext{
Directora de la BHM, Ilda María del Rosario Pérez García, por las facilidades que me brindó para consultar y reproducir ese material. Y a Héctor Urzáiz, que me ayudó en la lectura de algunos nombres de los firmantes de censuras.

4 alcacer: El alcacer, amén de ser la cebada, que sirve para engordar y purgar a caballos y mulas, forma parte en este caso de una frase hecha que hace referencia a lo incorregible y recalcitrante de la actitud de Laureta, ya que se empeña en ser alcahueta. Retozar el alcacer es estar excesivamente alegre, pero aquí adquiere claramente un doble sentido (nota de las editoras críticas, Di Pinto y de Miguel Magro, vv. 27-28, p. 350).
} 
por ejemplo, el parlamento de la Viuda en que se hace referencia a la misa [vv. 790-792], el de Margarita en que se refiere de forma despectiva a la situación de su tía y su marido [vv. 2550-2551] o la exclamación en que se menciona al diablo [vv. 2759-2760].

En algunas ocasiones, papeles anejos añaden versos y cubren una parte del contenido en ejemplares como el de Industrias contra finezas, impreso en Madrid por Antonio Sanz en 1751, conservado en la BHM Tea 1-120-20, c1, donde un fragmento de casi treinta versos se sustituye por el manuscrito de solo 7 , según se indica en las tablas. Por cierto, que en el cambio se pierde parte del enredo y del encanto de la comparación, como indica su editor crítico en nota:

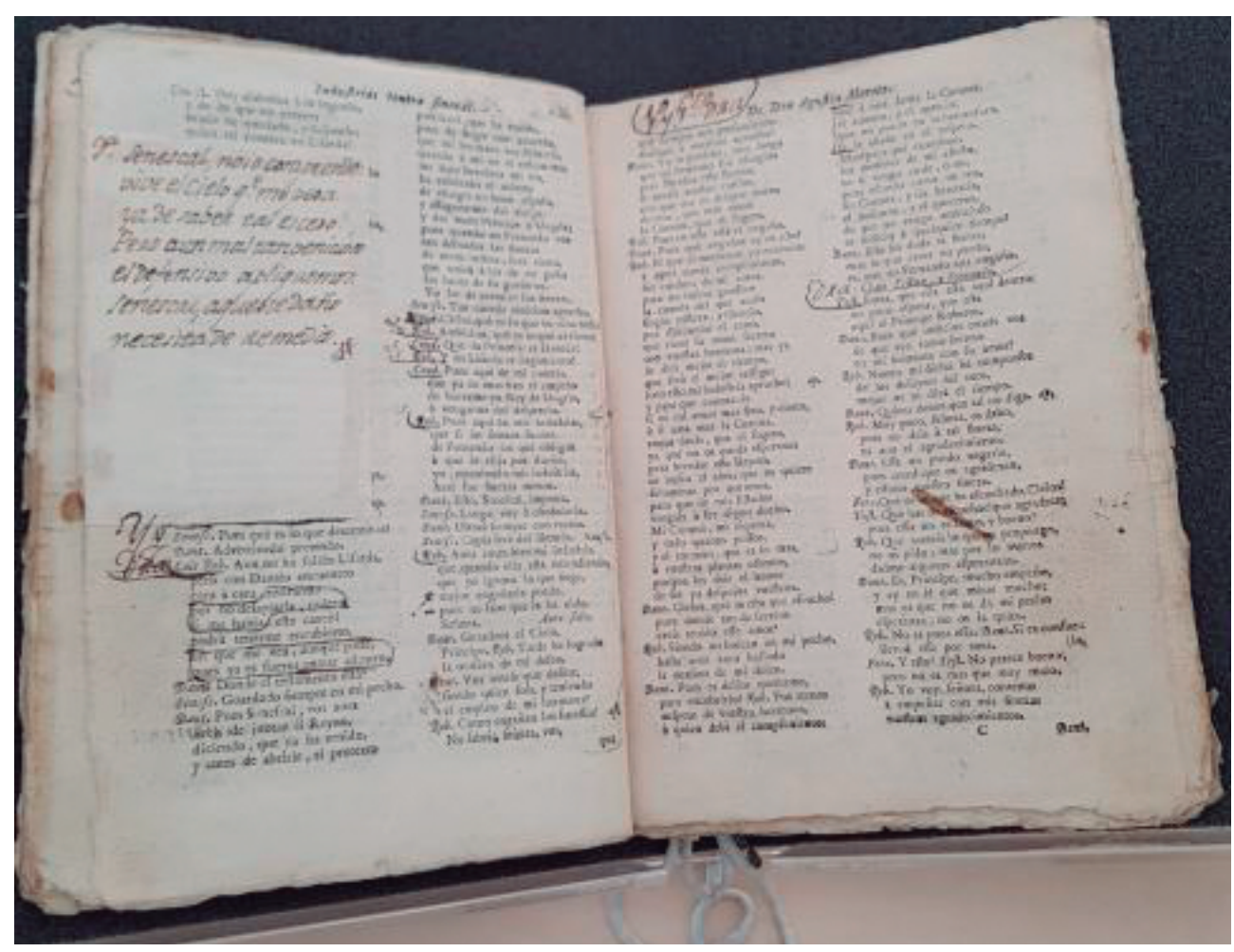

Ilustración 8 .

Industrias contra finezas, en Parte veinte y cuatro. Comedias nuevas y escogidas de los mejores ingenios de España, Madrid, por Mateo Fernández de Espinosa Arteaga, a costa de Juan de San Vicente, 1666.
Industrias contra finezas, Madrid, Antonio Sanz, 1751 


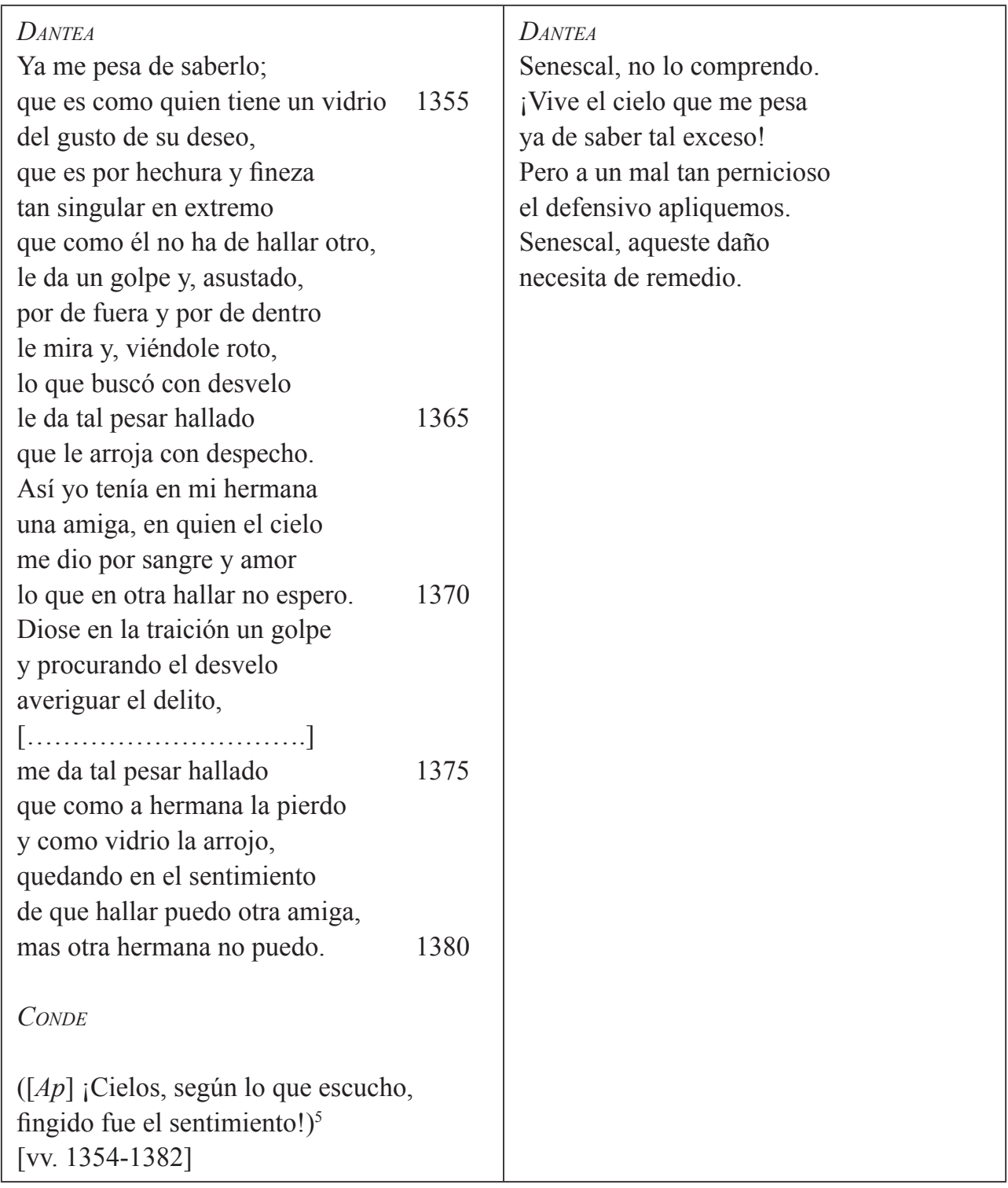

Sin embargo, más parece un recorte y reescritura de los actores que algo que tenga que ver con la censura moral, aunque en cierto modo es una censura literaria que buscaba, seguramente, acortar un pasaje casi un siglo después de la primera impresión.

\footnotetext{
5 El Senescal, escondido, se ha enterado en secreto de la conversación entre el Conde y Dantea. Dantea sabe que el Senescal les está escuchando. El Conde finge interés y fidelidad hacia Dantea. Esta sabe que es mentira, pero sigue el juego al Conde. El Conde sabe que todo es fingimiento por parte de Dantea. El enredo, pues, se complica, y el espectador observa todo con más conocimiento de los entresijos de las motivaciones de los personajes que cada uno de ellos. (Nota de Cortijo en su edición crítica, en preparación).
} 
En menos casos, las anotaciones manuscritas en los textos que se conservan dan lugar a pensar más en censuras estéticas que éticas. Veamos un ejemplo, en el que un texto añadido y pegado al impreso antiguo, mejora el original. Es el caso de $E l$ mejor amigo, el rey, impresa por Antonio Sanz en Madrid el año 1751, BHM Tea 1-127-12, a4. En el texto que aparece en la ilustración que sigue, se ve bien un caso de este tipo:

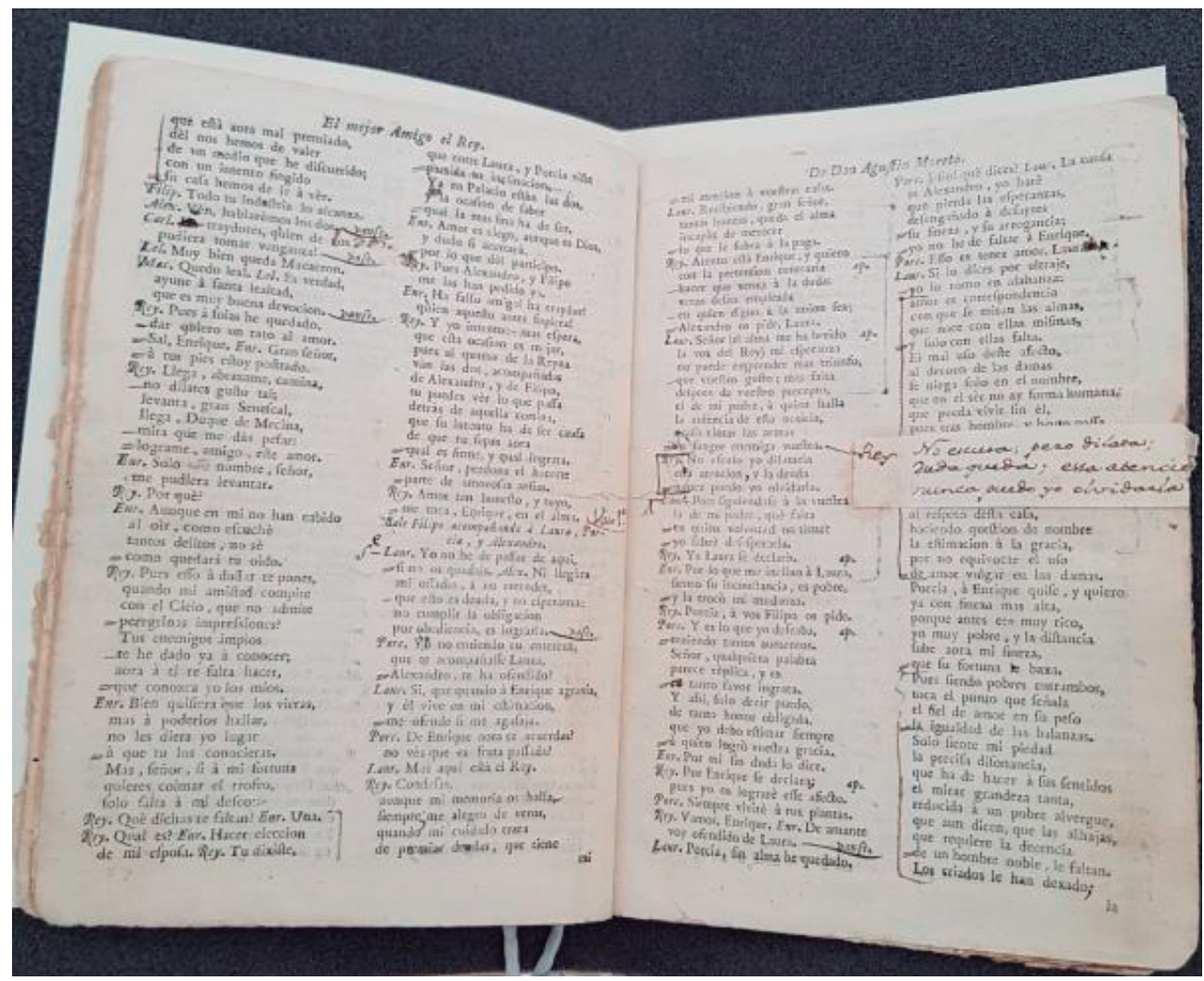

Ilustración 9.

El parlamento del Rey dice en la princeps:

REY ([Ap] No excusa, pero dilata. Duda queda esa atención, nunca puedo yo olvidarla.) [vv. 1248-1250]

Y eso es precisamente lo que aparece en el manuscrito, que intenta restituir esos versos, deturpados, en la edición de 1751 por estos otros:

REY

([Ap] No excuso yo dilatarla esta atención, y la deuda nunca puedo yo olvidarla. 
Por tanto, muy probablemente la compañía tuvo acceso al menos a dos textos de la comedia, uno primitivo, que trató de restaurar en este pasaje de un siglo más tarde. Se trataría de un caso de involución de un texto hacia el primitivo, más perfecto.

Veamos, para terminar este apartado, algún otro ejemplar de la obra con que comenzamos este análisis. Se trata de El lindo don Diego, que en varios impresos conservados en la Biblioteca Histórica Municipal tiene finales distintos. En uno de ellos, procedente de la Librería de Quiroga, calle de la Concepción Jerónima, BHM Tea 1-122-10c, aparece, además, la cruz de la censura en un diálogo entre Beatriz y Mosquito, que quizá pareció de contenido sexual demasiado explícito:

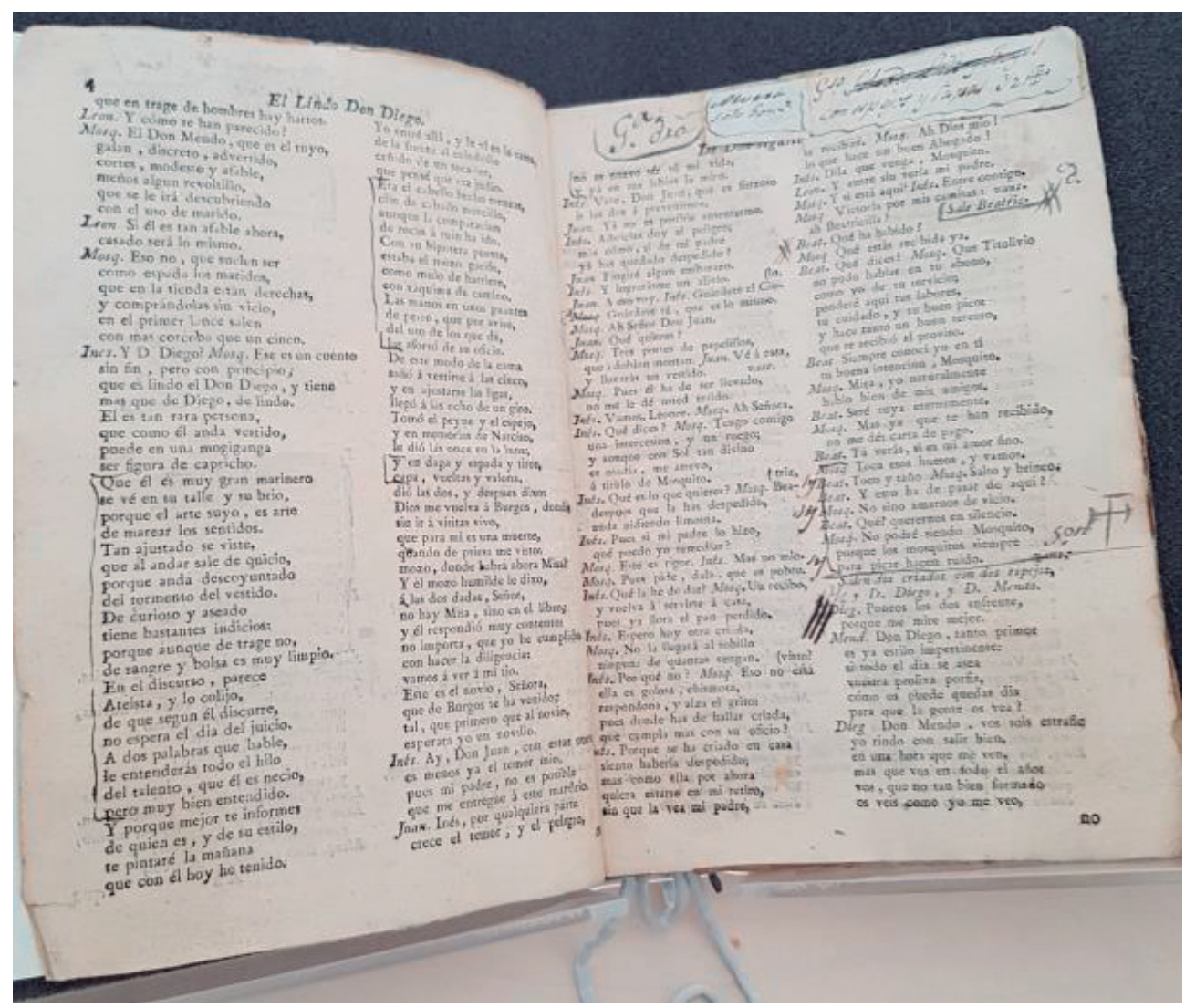

Ilustración 10.

El fragmento está en la columna de la derecha y el texto transcrito dice:

$\begin{array}{ll}\text { Mosquito } & \text { Toca esos huesos y vamos. } \\ \text { Beatriz } & \text { Toco y taño. }\end{array}$

6 Toco y taño: Se inicia un diálogo entre Mosquito y Beatriz construido en torno a los intereses sexuales que hay de trasfondo. El deseo de Mosquito sería obtener este tipo de favores como pago por sus exitosas gestiones para que aquella vuelva a ser admitida en casa de don Tello, y eso es lo que le declara veladamente. El uso de los dos 
Mosquito

BEATRIZ

Mosquito

BEATRIZ

Mosquito

BEATRIZ

Mosquito
Salto y brinco.

¿Y esto ha de pasar de aquí?

No, sino amarnos de vicio?

Pues querernos en silencio.

No podré siendo Mosquito.

¿Por qué no?

para picar $^{8}$ hacen ruido.

Porque los moscos

Vanse [vv. 465-472]

Sin embargo, el editor crítico, Francisco Sáez Raposo, señala la inclinación de Moreto a este juego de palabras con tocar los huesos, ofrecer el criado su mano a la criada - o algo más que la mano-, que está presente también en otras comedias moretianas; por ejemplo, en De fuera vendrá encontramos el siguiente fragmento:

LISARDO Yo te doy palabra y mano de ser tuyo a un mismo tiempo.

Doña Francisca Y yo de esposo la admito.

Alférez Pues la mano se dan ellos, dámela también.

MARGARITA

Sí haré.

Alférez, toca esos huesos, que yo seré la bandera [vv. 1366-1372]

Asimismo, en Trampa adelante se dice:

Millán Casilda, raros sucesos.

Casilda Tú la entraste por buen lado.

Millán A flux pintó de contado.

Casilda ¿Qué tocaré yo?

Millán

Estos huesos.

Casilda ¿Y no más?

MilláN

Te traeré luego

un laúd [vv. 912-917]

\section{La censura de comedias escritas en colaboración entre Moreto y otros ingenios}

Entre los testimonios que se conservan de comedias escritas por Moreto en colaboración con otros autores, está La fuerza del natural, en la que participó también Cáncer. En el ms. 15562 de la BNE, con letra de fines del siglo XVII y nota final que indica que el copista fue Juan García, varios pasajes aparecen marcados con corchete y la habitual cruz de la censura, esta vez al inicio y al final de cada uno de ellos.

sinónimos por parte de esta propicia la respuesta paralelística de aquel (nota del editor crítico, Sáez Raposo, v. 466, p. 369).

7 de vicio: "[...] sin necesidad, motivo o causa, o como por costumbre" (Aut.).

8 picar: Tras la aparentemente inocente vinculación que el gracioso establece entre este verbo y su nombre hay que entender, de acuerdo a las implicaciones eróticas subyacentes, otra de índole maliciosa, ya que picar era empleado frecuentemente en germanía como sinónimo de 'fornicar' (nota del editor crítico, Sáez Raposo, que cita a Alonso Hernández, v. 472, p. 370). 
El que más interesa ahora como muestra es aquel en que Carlos, el protagonista, describe las limitaciones de su hermano Julio, al que todos creen hijo de noble. Dice así:

Y así, señor, os diré

(Ap ¡albricias, intentos míos, que esto ha venido a medida de mis amantes delirios!) lo que siento y los remedios que pueden ser más activos. A dos puntos se reduce lo que dél he conocido: y el primero es que aborrece la enseñanza y, confundido con ella, le turba más que le compone el juïcio; y aquesto es desde su infancia, tanto que, si algo ha sabido, no a los preceptos lo debe, sino al uso repetido de verlo obrar a los otros; que, aunque el arte a corregirlo9 no basta, en la competencia suele avivar el sentido. [vv. 1581-1600]

No debió gustar al censor la crítica del hermano menos dotado o la referencia a lo vano de la enseñanza en quien no está capacitado para recibirla, el caso es que conservamos esa marca de censura. El mismo pasaje aparece con un "no" junto a otros varios en el editado en la imprenta de Antonio Sanz en Madrid, 1759, que se conserva en la BNE con signatura T 15037_9. En este impreso los versos marcados son numerosos, en especial en la primera jornada [vv. 277-288, 315-330, 495-508, 568-581, 1581-1602, 1971-1986] y se propone también un final distinto, al que antecede la cruz de la censura. Es, en concreto, el siguiente:

\begin{tabular}{|l|l|}
\hline $\begin{array}{l}\text { Parte quince / comedias nuevas, escogidas } \\
\text { de / los mejores ingenios de España, Madrid, } \\
\text { Melchor Sánchez, A costa de Juan de San } \\
\text { Vicente, 1661, fols. 91v-110. BNE R-22668. }\end{array}$ & Antonio Sanz, Madrid, 175034-9 \\
\hline $\begin{array}{l}\text { Y de Cáncer y Moreto } \\
\text { fin aquí las plumas dan, } \\
\text { probando que en todo sobra } \\
\text { la fuerza del natural. [vv. 2869-2872] }\end{array}$ & $\begin{array}{l}\text { Con esto acabado está. } \\
\end{array}$ \\
& Señores, no nos cansemos, \\
& que es locura sin igual \\
violentar en ningún caso \\
la Fuerza del Natural. \\
\hline
\end{tabular}

9 arte: aquí, con el sentido de instrucción, enseñanza reglada y ajustada (nota del editor crítico, García-Reidy, v. 1598 , p. 560). 
También en el impreso de La fuerza del natural, que se conserva en la BHM Tea 1-30-9, a2 parece haber marcas de censura. Los noes afectan al siguiente pasaje:

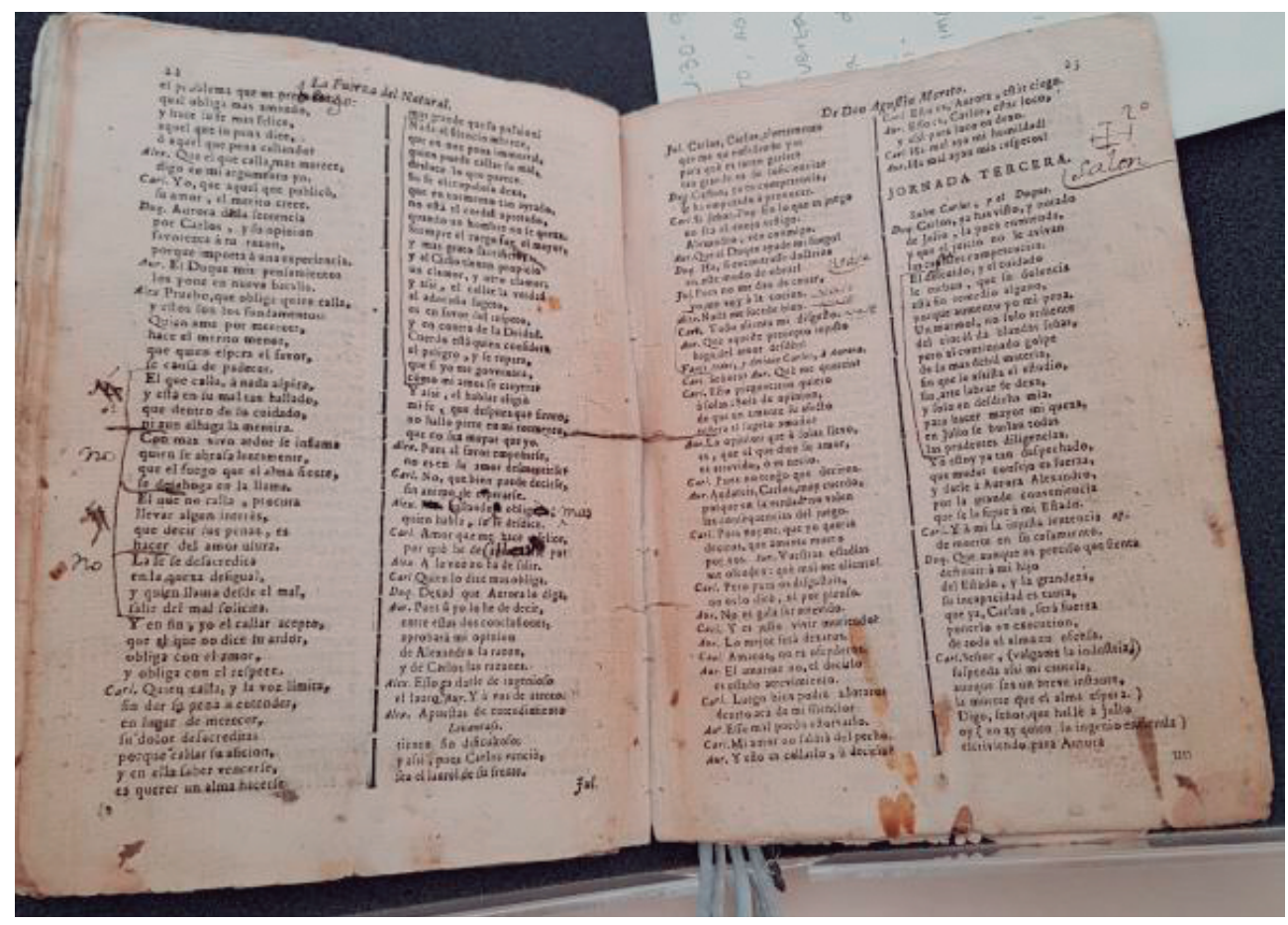

Ilustración 11.

El que calla a nada aspira y está en su mal tan hallado que dentro de su cuidado ni aún le halaga la mentira. Con más vivo ardor se inflama quien se abrasa lentamente, que el fuego que el alma siente se desahoga en la llama.

El que no calla procura llevar algún interés, que decir sus penas es hacer del amor usura. La fe se desacredita en la queja desigual, y quien llama desde el mal salir del mal solicita. [vv. 1939-1954] 
La reflexión sobre el callar/decir está puesta en boca de Alejandro, duque de Urbino, en un pasaje bastante extenso. No muy lejos de él, se recorta también un fragmento de versos que dice Carlos, como si la retórica del texto impreso resultara cansada o enfadosa no sé si a la censura o a una nueva representación en el siglo XVIII. Para que quien lee esto pueda juzgar, se copia el siguiente pasaje que tiene un corchete a la izquierda:

Nada el silencio merece, que, en una pena inmortal, quien puede callar su mal desluce lo que padece; su fe escrupulosa deja, que en tormento tan airado no está el cordel apretado cuando un hombre no se queja. Siempre el ruego fue el mayor y más grato sacrificio, $\mathrm{y}$ al cielo tienen propicio un clamor y otro clamor. Y así, el callar la verdad al adorado sujeto es en favor del respeto y en contra de la deidad. Cuerdo está quien considera el peligro y se repara, que, si yo me gobernara, ¿Cómo mi amor se creyera? [vv. 1967-1986]

En esta misma línea todavía en las dos páginas que sirven aquí de ilustración, se ve acortado el parlamento del Duque al inicio de la jornada tercera. El fragmento que se señala con corchete es este:

El descuido y el cuidado le turban, que su dolencia está sin remedio alguno porque aumente yo mi pena. Un mármol no solo al diente del cincel da blandas señas, pero al continuado golpe de la más débil materia, sin que le asista el estudio, sin arte labrar se deja; y solo en desdicha mía, para hacer mayor mi queja, en Julio se burlan todas las prudentes diligencias. [vv. 2069-2082] 
El lamento del Duque sobre las limitaciones de Julio, se entiende también sin estos versos, tomando solo los anteriores y los que le siguen, de modo que es posible proponer que su señalización no corresponde a la censura moral sino a la estética, en un deseo de hacer más ligero el texto al público de un siglo más tarde.

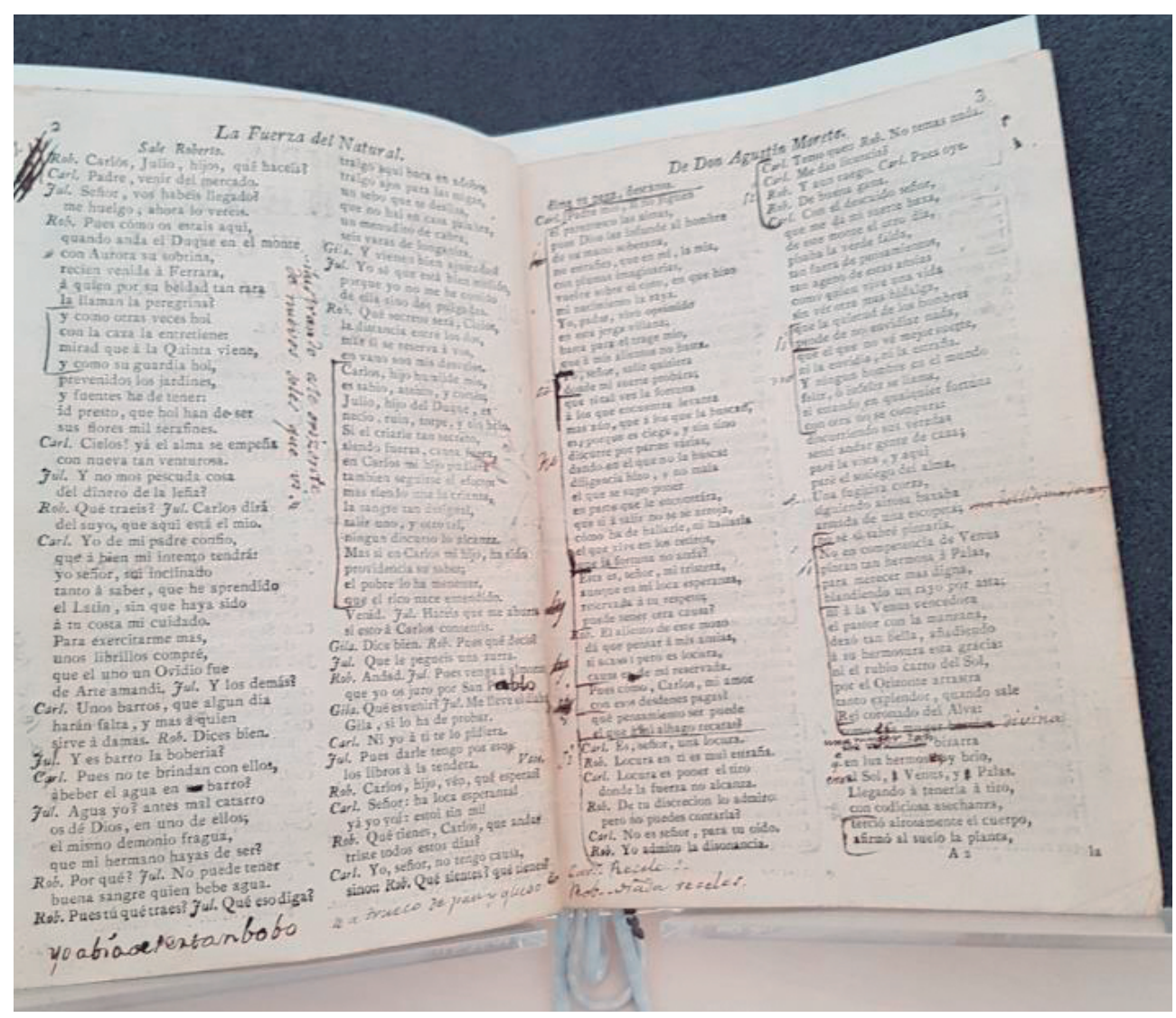

Ilustración 12.

Pero en no pocas ocasiones, estos recortes afectan a elementos importantes para la comprensión del texto. Es el caso del ejemplar impreso de esta misma obra, $\mathrm{La}$ fuerza del natural, editado en 1793 y en venta en la librería de Quiroga, hoy en BHM Tea 1-30-9, a2, donde se encuentran páginas llenas de anotaciones, como la que se copia. En ella se puede ver de qué manera se sugiere sustituir una serie de versos vitales para marcar la personalidad de los supuestos hermanos, por dos versos muy indeterminados. Los marcados con corchete a la izquierda decían:

Carlos, hijo humilde mío, es sabio, atento y cortés; Julio, hijo del Duque, es necio, ruin, torpe y sin brío. Si el criarle tan secreto, 
siendo fuerza, causa fuera, en Carlos, mi hijo, pudiera también seguirse el efeto; mas siendo una la crianza, la sangre, tan desigual, salir uno y otro tal ningún discurso lo alcanza.

Mas si en Carlos, mi hijo, ha sido providencia su saber, el pobre lo ha menester, que el rico nace entendido. [vv. 117-132]

Y los que se proponen manuscritos al margen como sustitutivos dicen: "ilustrando este horizonte / de nuevos soles que vi”.

En la página que sigue, y que se puede ver en la ilustración de arriba, un "No" encuadra estos versos en que Carlos reflexiona sobre la envidia y sus efectos:
que la quietud de los hombres
pende de no envidiar nada,
que el que no ve mejor suerte
ni la envidia, ni la daña.
Y ningún hombre en el mundo
feliz o infeliz se llama
si, estando en cualquier fortuna,
con otra no se compara. [vv. 213-220]

El resultado de la observación de estos y otros pasajes marcados en el impreso que se conserva en la BHM permite afirmar que los corchetes se sitúan en parlamentos generalmente largos y que pueden tratarse de indicaciones para los comediantes de posibles supresiones, en vistas a hacer más ágil la representación.

El príncipe perseguido, escrita por tres ingenios, tiene en el ejemplar sin colofón que se conserva en la BHM (Tea 1-55-5, a2), anterior a 1814, numerosos fragmentos con corchete a la izquierda, sin que sea posible saber si son marcas de censores o de la propia compañía de actores ${ }^{10}$. Solo en un caso aparece el "No" antes del corchete izquierdo. Se trata de un fragmento en que se anuncia que el Gran Duque ha muerto y exponen su dolor varios de los nobles asistentes: Ladislao, Elena, Filipo y también Jacobo Mauricio, que une al dolor el temor, porque va a abrir el testamento y no sabe el papel que tendrá en él. Si hubiera que entender este "No" como escrito por la censura, podría interpretarse que esta quisiera obviar las manifestaciones de dolor y temor tras la muerte del noble, y la avaricia de Jacobo Mauricio ante el testamento aún cerrado. Sin embargo, no dejan de extrañar los muchos corchetes en esta jornada del impreso. Valga destacar también el final paralelo que se escribe a mano cuando termina el impreso. Este dice en boca de Demetrio:

10 Sí hay constancia de la censura seiscentista de esta comedia en otro manuscrito conservado en la BNE, con licencias de 1645 y 1650; pueden verse sus interesantes detalles en la base de datos CLEMIT (http://buscador. clemit.es/obra.php?id=271). 
Y aquí el perseguido ponga

fin a sus adversidades

y los que escriben su historia

en el perdón de sus yerros

vuestra piedad reconozcan.

Mientras que en el impreso conservado en la BHM cambian los tres versos últimos:

Y aquí el perseguido ponga

fin a sus adversidades,

para que sirva su historia

de ejemplo a los que, tiranos,

osan usurpar coronas.

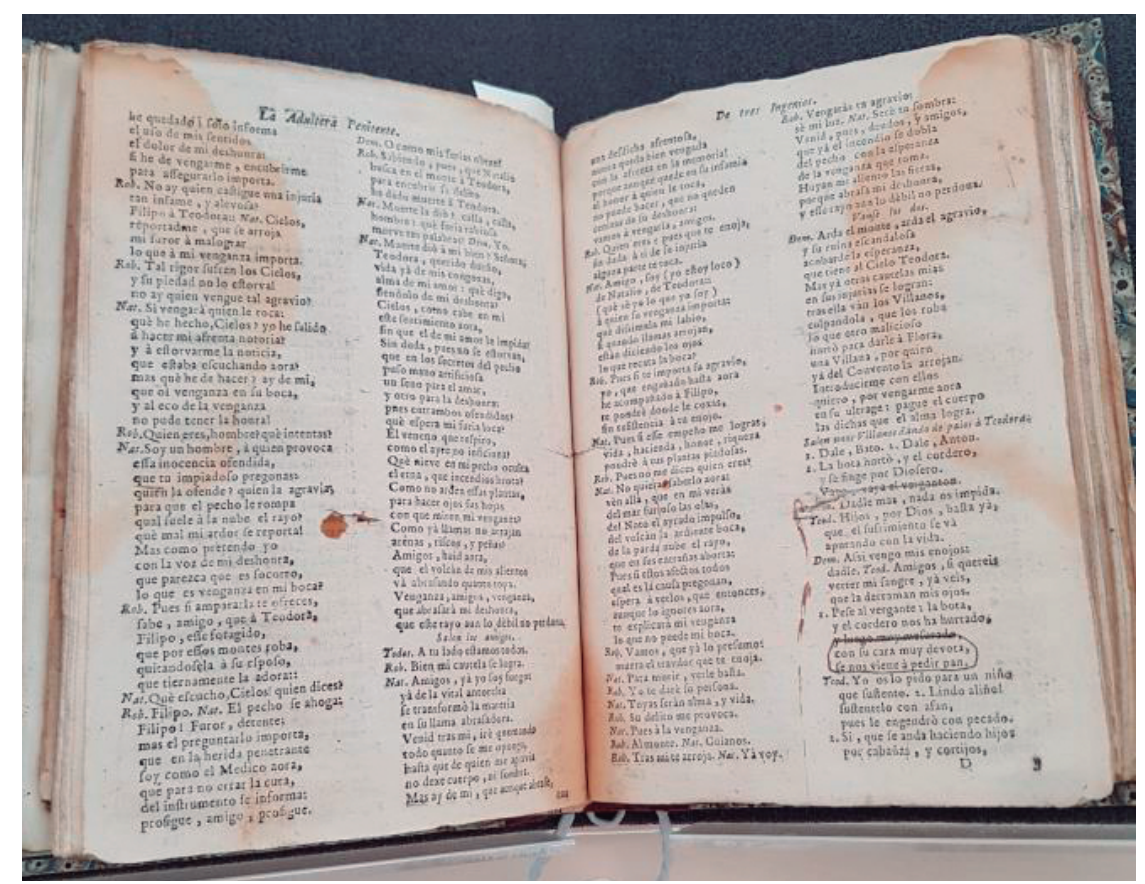

Ilustración 13.

Con ellos, la pedagogía a los nobles aumenta y los versos finales tienen tono de moraleja.

La adúltera penitente, de tres ingenios: Cáncer, Moreto y Matos, impresa en la imprenta de Antonio Sanz, 1738 (BHM MR 575), contiene versos enjaulados, que parecen corresponder a marcas de censura ${ }^{11}$, pues se refieren a la crítica de un personaje sobre otro, al que acusa de hipócrita:

11 También hay constancia en la base de datos CLEMIT de la censura de esta comedia en 1669 (http://buscador. clemit.es/obra.php?id=184). 
En concreto, los dos versos son los que dicen: "con su cara muy devota, / se nos viene a pedir pan" [vv. 2316-2317], y se encuentran incluidos en un fragmento que tiene un corchete a la izquierda y, a partir del v. 2325 hasta el final del que aquí se copia, hay un "Sí", que puede denotar un cambio de criterio en que se representaran esos versos.

\begin{tabular}{|c|c|}
\hline MONIO & ¡Dalde más! ¡Nada os impida! \\
\hline TEODORA & $\begin{array}{l}\text { Hijos, por Dios, ibasta ya!, } \\
\text { que el sufrimiento se va } \\
\text { apurando con la vida. }\end{array}$ \\
\hline DEMONIO & $\begin{array}{l}\text { ([Ap] Así vengo mis enojos.) } \\
\text { ¡Dalde! }\end{array}$ \\
\hline TEOdora & $\begin{array}{l}\text { Amigos, si queréis } \\
\text { verter mi sangre, ya veis } \\
\text { que la derraman mis ojos. }\end{array}$ \\
\hline [VILLANO] 1 & $\begin{array}{l}\text { ¡Pesia al bergante! La bota } \\
\text { y el cordero nos ha hurtado, } \\
\text { y luego muy mesurado, } \\
\text { con su cara muy devota, } \\
\text { se nos viene a pedir pan. }\end{array}$ \\
\hline TEODORA & $\begin{array}{l}\text { Yo os lo pido para un niño } \\
\text { que sustento. }\end{array}$ \\
\hline [VILLANO] 2 & $\begin{array}{l}\text { ¿Lindo aliño! } \\
\text { Susténtelo con afán, } \\
\text { pues le engendró con pecado. }\end{array}$ \\
\hline [Villano] 1 & $\begin{array}{l}\text { Sí, que se anda haciendo hijos } \\
\text { por cabañas y cortijos, } \\
\text { iy parece acaponado! }\end{array}$ \\
\hline Demonio & $\begin{array}{l}\text { Ese sufrimiento en vos } \\
\text { de vuestra culpa es testigo; } \\
\text { bien merecéis tal castigo. }\end{array}$ \\
\hline $\begin{array}{l}\text { TEODORA } \\
\text { [VILLANo] } 1\end{array}$ & $\begin{array}{l}\text { Sea por amor de Dios. } \\
\text { Y a Florilla cada día } \\
\text { nos lleva. Al abad nos vamos, } \\
\text { que, si noticia le damos } \\
\text { de aquesta bellaquería, } \\
\text { él le mandará quitar } \\
\text { el hábito }{ }^{13} \text {. [vv. 2305-2334] }\end{array}$ \\
\hline
\end{tabular}

El mismo testimonio impreso que se conserva en la BHM contiene algún fragmento más que no debió de ser del agrado de la censura, por ejemplo, el que está en

12 Lindo aliño: "frase irónica con que se explica no encaminarse bien lo que se pretende u desea" (Aut., s.v. "Qué gentil aliño”). Comp. Moreto, El defensor de su agravio, vv. 1578-1581: “AlejAndro. Sí lo estoy [triste y suspenso], y es porque pienso / que no soy quien era ahora. / [...] Comino. ¡Lindo aliño / trae con dudas semejantes!".

13 él le mandará quitar / el hábito: parece darse a entender que, a pesar de haberla expulsado del convento, el abad permitió a Teodora mantener el hábito de fraile, de tal modo que, quitárselo, aún supondría más castigo (nota del editor crítico, Rodríguez-Gallego, vv. 2333-2334, p. 147). 
boca del Villano 1 en respuesta al Abad: "Sí, padre. A Flora ha llevado / y un cordero nos ha hurtado, / y la bota, que es peor" [vv. 2872-2874].

Como se puede observar, lo que atrae la pluma del censor son los pequeños "guiños" del dramaturgo en que se pone un poco en berlina la "devoción" y la broma en la que lo material: "la bota" parece ser más importante que la mujer.

En El rey Enrique el Enfermo, de varios ingenios, sorprende un papel anejo en el ejemplar impreso en Valencia, en la imprenta de la viuda de Joseph de Orga el año

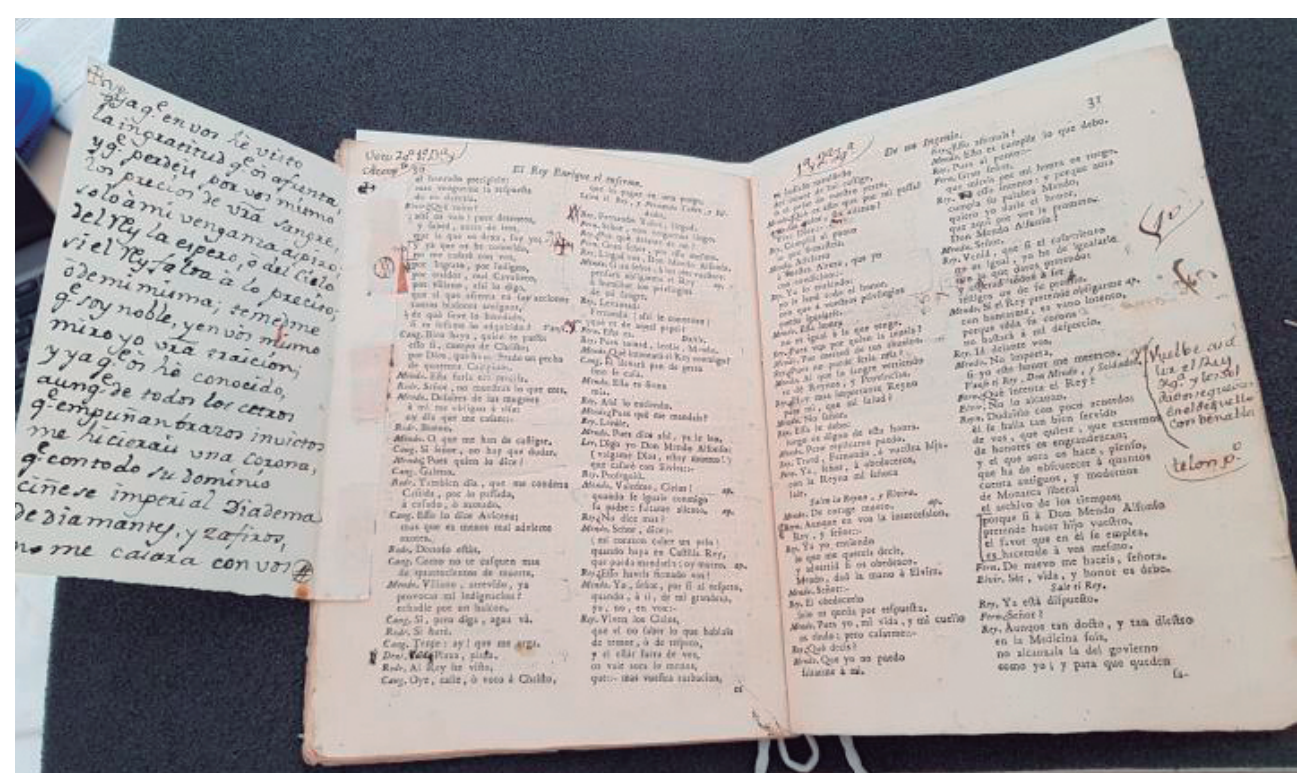

Ilustración 14.

1768 (BHM Tea 1-142-14, a1), que añade contenido, si bien no es posible delimitar por completo si el añadido es de la censura o de los actores, aunque quizá que sea de estos últimos ${ }^{14}$. De todos modos, se deja aquí un testimonio visual de este addenda, aunque no se comente:

De La mejor luna africana, la obra escrita por el mayor número de colaboradores que trabajaron en consuno en todo el Siglo de Oro, nueve, existen dos ejemplares que creemos no analizados hasta ahora en lo que tiene que ver con la censura ${ }^{15}$. El primero de ellos se imprimió en Valencia, por la viuda de Joseph de Orga en 1764 y tiene signatura BHM Tea 1-47-3a1. En él hay varios pasajes entre corchetes. Nos interesa uno en especial, en el que el pasaje completo parece anularse con los dos versos manuscritos en el margen derecho. El texto con corchete a la izquierda dice lo siguiente:

14 Hay en la base de datos CLEMIT un estudio de la censura de esta comedia en el siglo XVII (http://buscador.clemit. es/obra.php?id=191).

15 Hay en CLEMIT una breve reseña de la censura de esta comedia en 1680 (http://buscador.clemit.es/obra. php?id=114). 


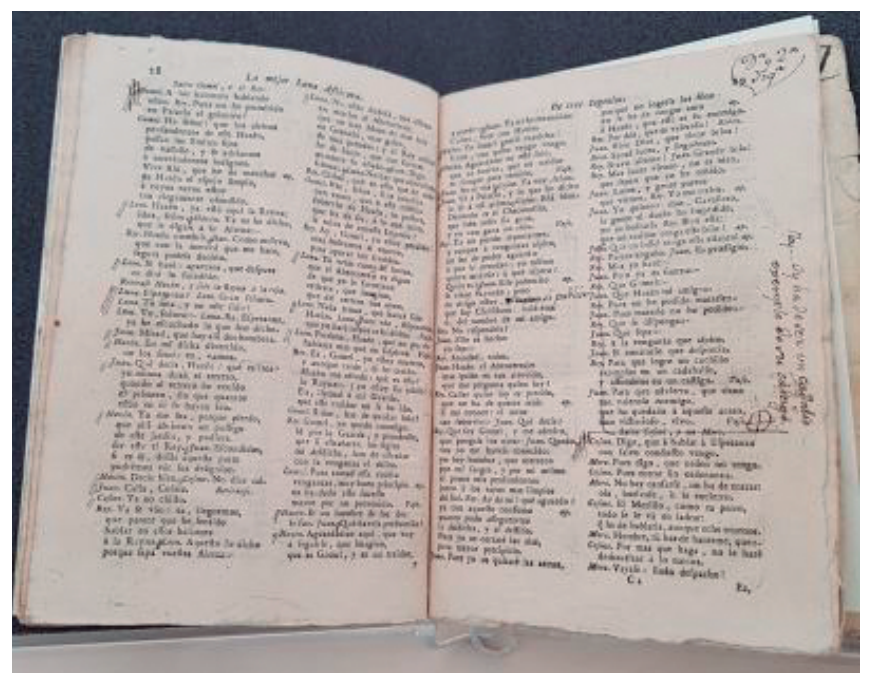

Ilustración 15.

\begin{tabular}{ll} 
JUAN & (Ap iQue un infiel tenga este aliento!) \\
REY & Parece engaño. \\
JUAN & \multicolumn{1}{c}{ Es prodigio. } \\
REY & Mas yo haré. \\
JUAN & \multicolumn{1}{c}{ Pero ya es fuerza... } \\
REY & Que Gomel... \\
JUAN & \multicolumn{1}{c}{ Que Hazén, mi amigo... } \\
REY & Pues no he podido matarle. \\
JUAN & Pues herirle aún no he podido. \\
REY & Que se disponga... \\
JUAN & A la venganza que aspiro. \\
REY & El contrario que desprecia. \\
JUAN & Para que logre un cuchillo, \\
REY & ejemplos en un cadahalso \\
& $\begin{array}{l}\text { y asombros en un castigo. Vase } \\
\text { Para que advierta que tiene } \\
\text { JUAN }\end{array}$ \\
& $\begin{array}{l}\text { tan valeroso enemigo, } \\
\text { que ha quedado aqueste acero, }\end{array}$ \\
& si no victorioso, vivo. Vase [vv. 1661-1676]
\end{tabular}

El que se incorpora al margen para sustituirlo está puesto en boca del Rey y se uniría al parlamento suyo anterior a este pasaje. Dicen los dos versos en cuestión: "Hoy ha de ser un cadalso / ejemplo de su castigo", con lo que se sintetiza el castigo y se refrenda el poder del rey para ordenarlo.

El segundo ejemplar de La mejor luna africana al que conviene referirse es al que se conserva en la BNE T 55269-2, también impreso en Valencia por la viuda de Joseph de Orga en 1764. Es, por tanto, un texto conservado de la misma edición que el anterior, pero el censor ha variado y no coinciden por completo los corchetes de la 
izquierda ni los enjaulados. Por ejemplo, el "Juro a Dios" [vv. 1223, 1306, 1441] que se pone circunscrito en este ejemplar en boca de Juan en tres ocasiones, no lo está en el testimonio que se conserva en la Biblioteca Histórica Municipal. Tampoco allí se redondea el "divino" relativo al sol [v. 1288] ni el "iCuerpo de Cristo!" [v. 1504] ni el sustantivo "demonio" [v. 1610]. Hasta cierto punto, podríamos decir que el censor que examinó el impreso que se conserva en la Biblioteca Nacional fue más riguroso en su tarea.

Y volviendo para terminar a la comedia escrita en solitario por Moreto, El lindo don Diego, observemos lo que el tiempo hizo en sus versos finales. Si la princeps del siglo XVII acababa:

$\begin{array}{ll}\text { Mosquito } & \begin{array}{l}\text { Aquí no hay a qué apelar, } \\ \text { que no lo sufriera el pueblo }\end{array} \\ \text { Don Diego } & \text { Pídase }^{17} \text { si quedo mal. } \\ \text { Mosquito } & \text { Y castigado este necio }^{\text {a gusto de los oyentes, }} \\ & \text { aquí, con aplausos vuestros, } \\ & \text { dichosamente el poeta } \\ \text { da fin al "Lindo don Diego". [vv. 3193-3200] }\end{array}$

En su lugar, se hacen añadidos manuscritos al menos en dos de los ejemplares consultados, correspondientes a los siglos XVIII y XIX, parece que con el fin de ampliar ese final y dar mayor protagonismo al figurón: El primero de ellos es el editado en la imprenta de don Francisco de Tójar, Salamanca, que trabajó entre 1786 y 1799, y se conserva en la BHM, Tea 1-122-10a:

$\begin{array}{cl}\text { Mosquito } & \text { Aquí no hay que apelar. } \\ & \text { Esto ha sido un gran enredo } \\ \text { que los dos hemos fraguado } & \text { para estorbar el intento } \\ & \text { que tenía de entregaros } \\ \text { su hija el señor don Tello. } & \text { Y así, condesita, toca, } \\ & \text { que esto no tiene remedio. } \\ & \text { Pues, señor, vaya con Dios. } \\ \text { DiEGO } & \text { Con que tú, por lo que veo, } \\ \text { eres condesa por tabla } \\ \text { y fregona por derecho. } \\ \text { Inés casa con don Juan } \\ \text { y doña Leonor con Mendo, } \\ \text { y yo quedo sin ninguna } \\ \text { por ser un gran majadero } \\ \text { que no conocí el engaño; }\end{array}$

16 el pueblo: 'el público'. A pesar de que don Diego, en el verso anterior, muestra su desacuerdo y se queja por el engaño sufrido, Mosquito zanja aquí la cuestión, alegando que la paciencia de los espectadores, que darían por bueno el escarmiento al lindo, no toleraría una prolongación del argumento sustentada en la demanda de este (nota del editor crítico, Sáez Raposo, v. 3194, p. 490).

17 Pídase con zeugma. 
sacando de todo ello,

que yo estoy aquí de más.

Mas, ¿qué importa todo esto

si en presentándome en Burgos

tendré marquesas a cientos,

que todas mueren por mí,

pues lo lindo que Dios me ha hecho

es cosa para admirar?

Y nada tendrá de nuevo

que si me ven veinte mozas

mañana haya veinte entierros

porque no las haga caso.

Y algunas habrá aquí dentro

que estarán muertas de amor

y ya perdidas de celos

solo de verme las piernas.

Pero me marcho al momento

y si quieren pretenderme,

por memoriales espero

que me dirijan a Burgos

con sobre al Lindo don Diego.

En el ejemplar de la BHM, Rea 1-122-10-c2, sin que se recoja en la edición crítica de esta comedia, es de interés que al terminar los versos añadidos aparece como fecha de lo manuscrito el 18 de junio de 1848 y las iniciales J.A.B.C. Dicen los versos de este final:

Mosquito Esto ha sido un gran enredo

que los dos hemos fraguado

para estorbar el intento

que tenía de entregaros

su hija el señor don Tello.

Y así, condesita, toca.

¿Con que, según vamos viendo,

eres condesa por tabla

y fregona por derecho?

¡Buena fortuna lograba

si no se declara el enredo!

Tú, Inesilla, has acotado

al señor don Juan, ¿no es esto?

¿Y tú, Leonor, a mi primo?

Sacando de todo ello

que yo estoy aquí de más

y eso para mí es lo menos,

pues solo con presentarme

cual yo soy en los paseos

tendré novias a millares

y lograré ser el dueño 


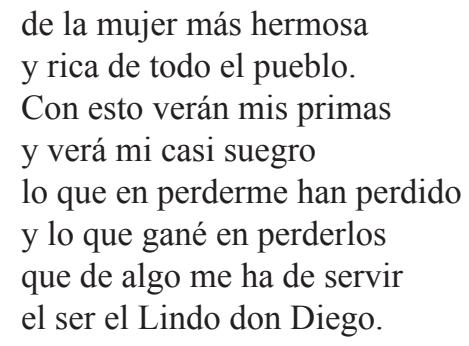

\section{Conclusiones}

A la luz de los textos examinados, varias cuestiones pueden deducirse: en primer lugar, el interés de las notas finales manuscritas por los censores en diversos años y siglos, que nos dan juicios - a menudo estereotipados, pero eso es también un dato de interéssobre la comedia que han revisado. Sus marcas pueden estar o no manuscritas a través de corchetes situados normalmente a la izquierda de versos o pasajes amplios de la obra examinada, en los que se indica "No", además de por la cruz que marca su actuación.

Existen, desde luego, marcas de censores que piden que se supriman pasajes con exclamaciones inapropiadas por referirse a temas o elementos sagrados, como la invocación al diablo en Trampa adelante: "Llévense os diabros la casa / e a min porque vine acá" [vv. 1397-1398], que cierra el debate entre don Juan, el gracioso Millán y un esportillero que reclama su paga, o el juramento en La mejor luna africana que se condena tres veces: "Juro a Dios" [vv. 1223, 1306, 1441]. De signo similar sería la manera en que se censura con la calificación de "devota" en mal sentido a uno de los personajes de La adúltera penitente: "con su cara muy devota, / se nos viene a pedir pan" [vv. 2316-2317]. También el recorte afecta a pasajes de contenido sexual que se atemperan en un añadido manuscrito, como el ya comentado de La misma conciencia acusa, en que Tirso, villano, recrimina a la también villana Laureta: "que a más de ser alcahueta, / os retoza el alcacer", sobre el que se escribe: "que huyendo de la alcahueta / sois lo que no queréis ser". Y, en menos casos, el acotado por un "No" es un pasaje completo que deja en mala situación a uno de los protagonistas (La fuerza del natural), aunque en esta acción se pierda una carga muy importante del contenido de la pieza.

Pero esos noes tienen también otros sentidos, además de los de la censura moral. Los observamos en pasajes largos que quizá el director o un miembro de la compañía teatral marcó para que los comediantes no pronunciasen en escena y se aligerase así la representación, una vez cambiado el siglo y los gustos -y quizá la paciencia- de los espectadores. Se incluye a veces un texto manuscrito, mucho más exiguo que, como una sentencia, reúne lo anterior y da un tono moral al conjunto (La mejor luna africana). $\mathrm{O}$ la reducción afecta a un pasaje amplio, al que se limita en sus posibilidades poéticas con el esquilme que se traza, como se ha visto en el parlamento de Dantea en Industrias contra finezas, tan distinto en la versión de 1751 respecto a la de 1666, y en algunos fragmentos de los señalados en La fuerza del natural.

Y, si los noes invitan a suprimir versos, también corrigen amplificaciones que han traído el tiempo y manos ajenas sobre el texto original, como ocurre en Los mártires de Madrid. Además, algunos noes tienen detrás un vigilante del verso que al encontrar en un impreso versos deturpados, vuelve a un texto primigenio, recu- 
pera los versos correctos y los sobreescribe o escribe al margen, con el deseo de devolver a la obra su rigor primitivo (El mejor amigo, el rey). En esta línea, vuelve a su estado original un texto deturpado en el paso de una imprenta a otra (El mejor, amigo, el rey).

En ocasiones, dentro de este empeño por recuperar la obra más parecida a la original, el lector ve que se ha producido una amplificatio a posteriori en el texto manuscrito tardío y señala con "No" los pasajes que ve sobrevenidos respecto al texto inicial, como se explicó al hablar de Los mártires de Madrid.

Los cambios, atribuibles también a los comediantes, afectan a finales de comedias como El príncipe perseguido, en que se ponen palabras en boca de Demetrio que hacen terminar la obra de un modo más ejemplarizante en la suelta posterior que en la princeps. En otros casos, tan notables como El lindo don Diego, varían los versos con que finaliza la comedia en dos de los ejemplares localizados, correspondientes a los siglos XVIII y XIX, respectivamente, para adaptarlos a la iniciativa de una nueva compañía de representantes.

También podemos constatar que censores distintos que revisan una misma obra señalan con "No" pasajes diversos y a veces resultan más benévolos unos que otros, como se ha detallado al tratar La mejor luna africana.

En resumen y a la luz de lo anterior, observamos una vez más cuán delicadas son las cuestiones relativas a la censura, que tiene muchos sujetos: censores, fiscales, protectores de comedias y calificadores del Santo Oficio, pero también lectores que modifican los versos quizás para una nueva tirada en la imprenta, pero -sobre todopara una nueva representación, sin que sepamos si fueron dramaturgos o autores de compañías y comediantes, aunque más nos inclinamos por estos últimos, siempre ocupados en agradar a su público. En todo caso, la huella de estas acciones sobre los textos, plantea el texto dramático como objeto mutable en cierta medida, que se lee, mejora o, en ocasiones, se deturpa, pero siempre porque la letra del siglo XVII permanece viva y su autor son "legión".

\section{Bibliografía}

\section{Bibliografía primaria}

Moreto, Agustín, La adúltera penitente, ed. Fernando Rodríguez-Gallego, Alicante, Biblioteca Virtual Miguel de Cervantes, 2019, en Comedias de Agustín Mordo. Obras escritas en colaboración (Colección Digital Proteo 8), recurso web http://www.cervantesvirtual.com/ portales/agustinmordo/obra/la-adultera-penitente-942634. Letra de consulta: 3-III-2019.

- Antíoco y Seleuco, ed. Héctor Urzáiz Tortajada, en Comedias de Agustín Moreto. Primera Parte de comedias. Volumen III, dir. María Luisa Lobato, coord. Miguel Zugasti, Kassel, Reichenberger, 2011: 413-580.

- De fuera vendrá quien de casa nos echará, ed. Delia Gavela García, en Comedias de Agustín Moreto. Primera Parte de comedias. Volumen II, dir. María Luisa Lobato, coord. Judith Farré Vidal, Kassel, Reichenberger, 2010: 1-179.

- El defensor de su agravio, ed. Daniele Crivellari, Alicante, Biblioteca Virtual Miguel de Cervantes, 2016, en Comedias de Agustín Moreto (Colección Digital PROTEO, 2), Recurso web <http://www.cervantesvirtual.com/nd/ark:/59851/bmcc84b0>, Fecha de consulta: $17-X I I-2018$. 
- El desdén, con el desdén, ed. María Luisa Lobato, en Comedias de Agustín Moreto. Primera Parte de comedias. Volumen I, dir. María Luisa Lobato, Kassel, Reichenberger, 2008: 397-580.

- La fuerza del natural, ed. Alejandro García-Reidy, en Comedias de Agustín Moreto. Segunda Parte de comedias. Volumen V, dir. María Luisa Lobato, coord. Marcella Trambaioli, Kassel, Reichenberger, 2016: 465-657.

- Industrias contra finezas, ed. Antonio Cortijo, en Moretianos.com, Grupo de investigación PROTEO-Moretianos, Recurso web <http://www3.ubu.es/proteo/docs/Comedias/ Industrias.pdf $>$, Fecha de consulta: 17-XII-2018.

- El lindo don Diego, ed. Francisco Sáez Raposo, en Comedias de Agustín Moreto. Segunda Parte de comedias. Volumen VIII, dir. María Luisa Lobato, Kassel, Reichenberger, 2013: 327-523.

- Los mártires de Madrid, ed. Roberta Alviti, en Moretianos.com, Grupo de investigación PROTEO-Moretianos, Recurso web < http://www.moretianos.com/encolaboracion.php>, Fecha de consulta: 17-XII-2018.

- La mejor luna africana, ed. Juan Matas Caballero, en Moretianos.com, Grupo de investigación PROTEO-Moretianos, Recurso web < http://www3.ubu.es/proteo/docs/Comedias/ ClbMejorLunaAfricana.pdf $>$, Fecha de consulta: 17-XII-2018.

- El mejor amigo, el rey, ed. Beata Baczyńska, en Comedias de Agustín Moreto. Primera Parte de comedias. Volumen I, dir. María Luisa Lobato, Kassel, Reichenberger, 2008: 245- 580.

- La misma conciencia acusa, ed. Elena Di Pinto y Tania de Miguel Magro, en Comedias de Agustín Moreto. Primera Parte de comedias. Volumen II, dir. María Luisa Lobato, coord. Judith Farré Vidal, Kassel, Reichenberger, 2010: 331-502.

- El príncipe perseguido, ed. Beata Baczyńska, en Moretianos.com, Grupo de investigación PROTEO-Moretianos, Recurso web <http://www3.ubu.es/proteo/docs/Comedias/ ClbPrincipePerseguido.pdf $>$, Fecha de consulta: 17-XII-2018.

- Lo que puede la aprehensión, ed. Francisco Domínguez Matito, en Comedias de Agustín Moreto. Primera parte de comedias. Volumen IV, dir. María Luisa Lobato, coord. Javier Rubiera, Kassel, Reichenberger, 2010: 399-590.

- El rey don Enrique el enfermo, ed. Anna Benvenuti, en Moretianos.com, Grupo de investigación PROTEO-Moretianos, Recurso web < http://www3.ubu.es/proteo/docs/Comedias/ClbReyEnriqueEnfermo.pdf $>$, Fecha de consulta: 17-XII-2018.

- Trampa adelante, ed. Juan Antonio Martínez Berbel, en Comedias de Agustín Moreto. Primera Parte de comedias. Volumen III, dir. María Luisa Lobato, coord. Miguel Zugasti, Kassel, Reichenberger, 2011: 227-412.

\section{Bibliografía secundaria}

Urzáiz, Héctor, y Gema Cienfuegos (2013): “Texto y censura de una obra atribuida a Moreto: La adúltera penitente", eHumanista 23: 296-322. 
